\title{
Aftershock distribution of the 26 December 2004 Sumatra-Andaman earthquake from ocean bottom seismographic observation
}

\author{
Eiichiro Araki ${ }^{1}$, Masanao Shinohara ${ }^{2}$, Koichiro Obana $^{1}$, Tomoaki Yamada ${ }^{2}$, Yoshiyuki Kaneda ${ }^{1}$, \\ Toshihiko Kanazawa ${ }^{2}$, and Kiyoshi Suyehiro ${ }^{1}$ \\ ${ }^{1}$ IFREE, Japan Agency for Marine-Earth Science and Technology, 2-15 Natsushima-cho, Yokosuka, Kanagawa 237-0061, Japan
${ }^{2}$ Earthquake Research Institute, the University of Tokyo, 1-1-1 Yayoi, Bunkyo-ku, Tokyo 113-0032, Japan
}

(Received July 22, 2005; Revised December 2, 2005; Accepted December 3, 2005; Online published February 17, 2006)

\begin{abstract}
We deployed an OBS network in February-March 2005 in the rupture area of the Sumatra Andaman earthquake on 26 December 2004. We placed 17 short-term OBSs and two long-term OBSs, and recovered OBSs after observation for 19-22 days. The hypocenter distribution from 10-day data of 17 OBS revealed the detailed structure of aftershock seismicity offshore of Sumatra Island. Aftershock seismicity associated with the subducting slab starts $40 \mathrm{~km}$ inward from the Sunda trench axis; it ceases at $50 \mathrm{~km}$ depth beneath the Aceh Basin, approximately $240 \mathrm{~km}$ inward from the trench axis. Aftershocks in 120-170 km from the trench axis consist of a surface with a dip of 10-12 ${ }^{\circ}$ dominated by a dip-extension type mechanism. Beyond the southwestern edge of the Aceh Basin, the aftershock activity becomes higher, and dominated by dip-slip type earthquakes, with a slightly increased dipping angle of $15-20^{\circ}$. Three along-arc bands of shallow seismicity were identified at $70 \mathrm{~km}$ inward from the Sumatra trench, $110 \mathrm{~km}$ inward from the trench, and in the south of the Aceh Basin. These locations correspond to steep topographic slopes in the accretionary prism, suggesting the present evolutional activity of the accretionary prism offshore Sumatra Island.
\end{abstract}

Key words: Sumatra, Andaman, aftershock, seismicity, ocean bottom seismograph (OBS), accretionary prism, plate boundary.

\section{Introduction}

The Sumatra-Andaman earthquake of 26 December 2004 revealed an historically large seismic moment released beneath the seafloor $1200 \mathrm{~km}$ from offshore Simeulue Island south of Sumatra Island to the north of Andaman Island. That seismic moment engendered a devastating tsunami that killed more than 300,000 people. The earthquake has been analyzed extensively using various seismo-geodetic means such as teleseismic body waves (Ji, 2005; Yagi, 2005; Yamanaka, 2005), earth's free oscillation (Stein and Okal, 2005), and tsunami observed using satellite altimetry (Hirata et al., 2005). All analyses above are based on observed data that were taken remotely from the rupture area. With such observed data, it is difficult to infer the precise geometry of the earthquake faults that slipped during the earthquake. Many of those analyses subsumed the geometry of a plate boundary in which the rupture took place. They relied on results of Harvard CMT analyses or geometry of background seismicity. The former assumes that the entire rupture took place in a simple planar surface. The latter data (from such a catalog as Engdahl et al., 1998) has great limitations that are unavoidable from the scarce number of earthquakes observed during 40 years or so. It is especially difficult above $30 \mathrm{~km}$ to find an appropriate depth and dipping angle of the plate interface from the seismicity.

Copyright (c) The Society of Geomagnetism and Earth, Planetary and Space Sciences (SGEPSS); The Seismological Society of Japan; The Volcanological Society of Japan; The Geodetic Society of Japan; The Japanese Society for Planetary Sciences; TERRAPUB
Therefore, it is of great importance to observe seismic activity closely soon after a large earthquake to unveil the geometry and dynamics of the subducting plate in and around the rupture area. According to the Omori relation of aftershocks, aftershock activity will decay quickly with time. In Sumatra Island, the destructive damage of infrastructure due to the devastating tsunami made it difficult to install seismographic networks for aftershock survey. The depth accuracy of offshore seismic activity analyses from existing land data was very limited. Because of those limitations, we decided to bring a research vessel into the rupture area quickly to install a seismographic network of ocean bottom seismographs (OBSs).

After the Sumatra-Andaman earthquake on 26 December 2004, seismic observation using OBSs was carried out in the offshore northern part of the Sumatra Island, where a large co-seismic slip was inferred from teleseismic analyses. We laid an OBS network to determine the detail of aftershock seismicity. Purposes of this OBS observation are to determine the precise location of aftershocks around the area of the main shock. The precise image of aftershocks as well as those mechanisms should help us to delineate the geometry of the subducting oceanic plate that caused the Sumatra-Andaman earthquake, as well to assess possibilities for large aftershocks by recovery of subsurface faults.

\section{OBS Network and Data}

In all, 17 short-term OBSs from Japan Agency for Marine Earth-Science and Technology (JAMSTEC) and Earth- 


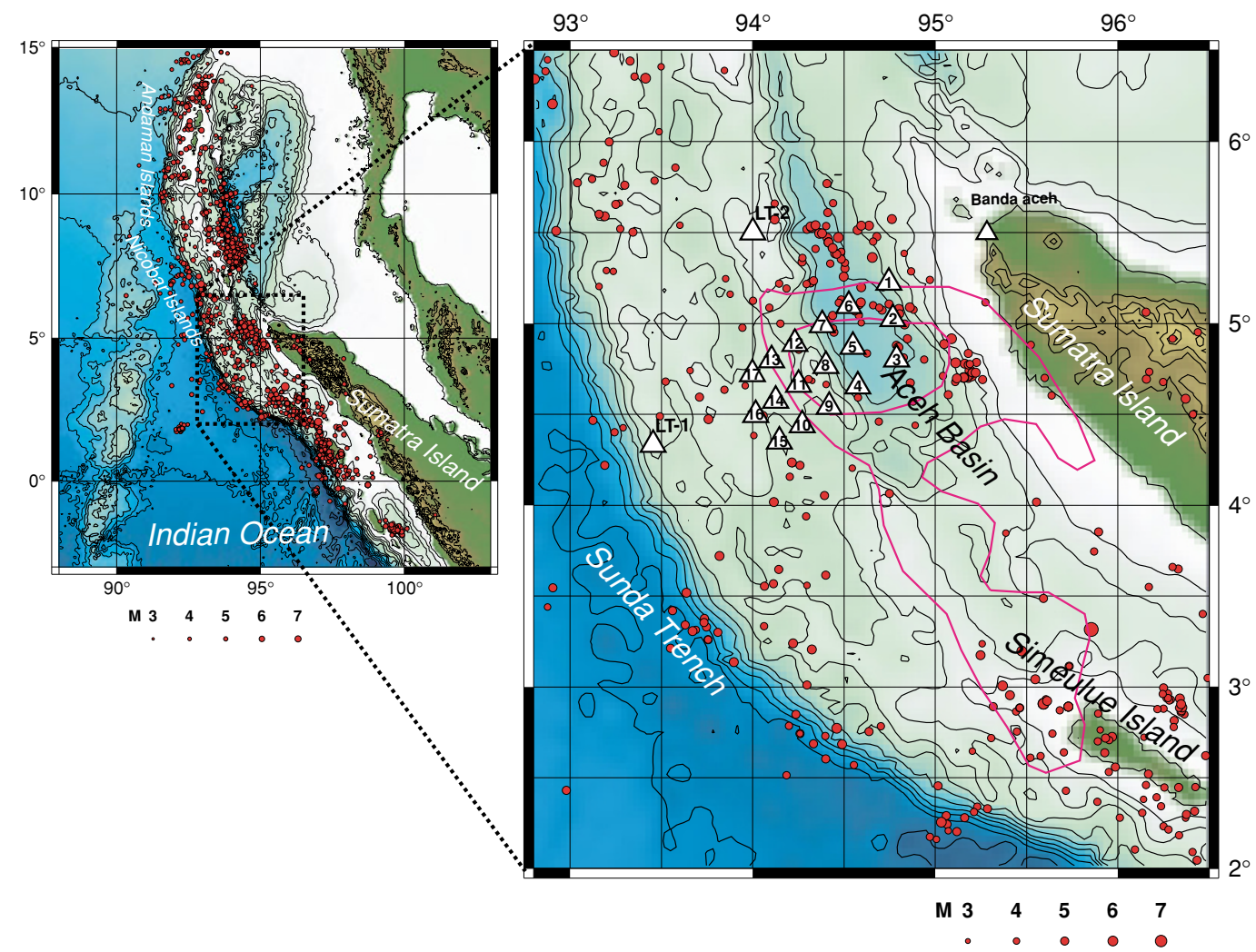

Fig. 1. Location map of OBSs. The OBSs are represented as triangles with station names. OBSs $1-17$ were recovered in the NT05-08 cruise for this study. LT-1 and LT-2 are the long-term OBSs. Banda Aceh station is a land seismic station maintained by the Meteorological and Geophysical Agency of Indonesia (BMG). Aftershocks from PDE catalog by USGS during 12/26/2004-4/17/2005 are plotted as red circles scaled by magnitude, as indicated at the bottom. Sizes of circles correspond to the reported magnitude. Purple contours show a slip distribution of the 26 December earthquake after Yagi (2005).

quake Research Institute, the University of Tokyo (ERI) as well as two long-term OBSs from ERI were deployed (Fig. 1) during the R/V Natsushima NT05-08 cruise of JAMSTEC.

The along-arc coverage of the deployed OBS network is approximately $50 \mathrm{~km}$. That coverage was restricted by the number of the available OBSs and the spacing required for precise determination of earthquake depths. Distances between stations were made shorter to the Sumatra trench. Such variable station-to-station distances were intended to better resolve depths of aftershocks in the subducting slab, and yet to offer wider network coverage with a limited number of OBSs. Distances are adjusted to be similar to the depth of the subducting plate boundary assumed from the seismicity catalog by Engdahl et al. (1998). The OBSs are aligned as three parallel arrays in $55^{\circ}$ of north, parallel to the dipping direction of the Wadati-Benioff zone.

The area of the short-term OBS network covers the area of seaward transition about $100 \mathrm{~km}$ to the Sumatra trench from a very large slip area in the main shock determined by Yagi (2005), as shown by contours in Fig. 1. The network location also corresponds to the area of large seafloor deformation inferred from tsunami waveform inversion by Hirata et al. (2005). The landward edge of the network is situated at the high aftershock activity area found from globally determined seismicity (PDE) by the United States Geological Survey. Using such seismicity data, the known aftershocks become few to the southwest of the network, although some were of indeterminate depth.

During the cruise, we recovered all 17 short-term OBSs. The observation period of the short-term OBSs was 20 February-13 March 2005 (19-22 days). One of the 17 OBSs did not start recording in the seafloor, but the remainder of the OBSs recorded good three-component seismograms. After observation until the end of July 2005, we recovered one of the long-term OBSs by R/V Baruna Jaya I-BPPT (Agency for the Assessment and Application of Technology, Indonesia). In all, we analyzed seismic data from the 17 OBSs deployed offshore of Sumatra Island. In each OBS record, more than 200 events were discernible as a daily average. In some OBSs $(9,11,12,14,15,16$, 17 in Fig. 1), periods of high noise occurred one or two times daily. Sites of the periodic high noise were situated in the shallower seafloor in outer-arc high mountains, implying that the seafloor tidal current was high in these locations. The tidal current in such a location was probably higher than on the flat seafloor such as at the bottom of the Aceh Basin.

\section{Analysis}

We identified earthquakes by comparing short-term and long-term averages of OBS records in the $4-15 \mathrm{~Hz}$ pass band. We identified events that were apparent at more than three OBS stations. Hypocenters were determined for the events identified from the OBS data from 20 February1 March. We also examined events located by USGS 
Table 1. Summary of travel time residuals and station correction. For each OBS, mean (O-C) and the root-mean-square residual (RMS) of the model to observation for $P$ and $S$ readings are listed along with station correction ( $P$ SC and $S$ SC, respectively).

\begin{tabular}{c|rcccrr}
\hline station & $P(\mathrm{O}-\mathrm{C})$ & $P(\mathrm{RMS})$ & $S(\mathrm{O}-\mathrm{C})$ & $S(\mathrm{RMS})$ & $P$ SC(s) & $S$ SC(s) \\
\hline OBS02 & -0.041 & 0.221 & 0.020 & 0.669 & 0.142 & -0.931 \\
OBS03 & -0.005 & 0.214 & 0.060 & 0.572 & 0.037 & -1.061 \\
OBS04 & 0.035 & 0.247 & 0.121 & 0.718 & -0.289 & -2.396 \\
OBS05 & 0.025 & 0.369 & 0.115 & 0.424 & 0.200 & -0.902 \\
OBS06 & -0.021 & 0.268 & 0.043 & 0.563 & 0.276 & -0.807 \\
OBS07 & 0.008 & 0.258 & 0.078 & 0.489 & -0.195 & -1.736 \\
OBS08 & 0.034 & 0.305 & 0.141 & 0.614 & 0.450 & -0.463 \\
OBS09 & 0.033 & 0.419 & 0.101 & 0.842 & 0.732 & 0.383 \\
OBS10 & 0.018 & 0.363 & 0.074 & 0.945 & -0.348 & -0.955 \\
OBS11 & 0.035 & 0.424 & 0.105 & 0.889 & 0.039 & -0.498 \\
OBS12 & 0.032 & 0.292 & 0.094 & 0.638 & 0.329 & -0.598 \\
OBS13 & 0.036 & 0.364 & 0.127 & 0.709 & -0.234 & -0.746 \\
OBS14 & 0.037 & 0.325 & 0.110 & 0.679 & -0.349 & -1.225 \\
OBS15 & 0.018 & 0.429 & 0.073 & 0.744 & -0.603 & -1.176 \\
OBS16 & 0.040 & 0.375 & 0.102 & 0.840 & -0.299 & -0.999 \\
OBS17 & 0.029 & 0.414 & 0.107 & 0.760 & -0.338 & -1.031 \\
LT-1 & -0.004 & 0.136 & -0.012 & 0.925 & 0.000 & -0.961 \\
\hline
\end{tabular}

throughout the OBS observation period from 20 February11 March to calibrate the hypocenter of globally determined earthquakes.

Location of earthquakes was performed using the maximum likelihood method by Hirata and Matsu'ura (1987) in a 1-D velocity model. Both $P$ and $S$ arrival picks were used in analyses. In results presented hereafter, we chose events that were located with accuracy of better than $10 \mathrm{~km}$ for both horizontal and depth.

There was no detailed known seismic structure in the area of the OBS network. The seismic velocity structure for the hypocenter determination was assumed as Fig. 2. Above 30 $\mathrm{km}$ depth, we assumed a structure similar to that offshore of Sumatra Island (SO138-03 in Kopp et al., 2001) further south of our observation area. Below $37 \mathrm{~km}$ depth, the $P$-wave velocity is similar to that of Kennett and Engdahl (1991). We assumed $V p / V s=\sqrt{3}$ for the entire model. After locating earthquakes, we inspected dependence of their traveltime misfit on epicentral distance for each OBS. No marked dependence was apparent except for OBS 8 and OBS 9 (Fig. 1), which had positive O-C, and OBS 15 and OBS 16, which had negative $\mathrm{O}-\mathrm{C}$ for larger epicentral distances. Even for these stations, the average deviation from our model is less than one second.

We applied station correction to $P$-phase and $S$-phase readings to take account of the effects of sediment cover and shallow structure that differ from station to station. The correction was obtained for each OBS by the average of the travel time differences of observation from those calculated for our structural model. After correction, the averaged difference between observations and calculations (Table 1) fell to within $0.05 \mathrm{~s}$ for $P$-phases and $0.15 \mathrm{~s}$ for $S$-phases. The root mean square (rms) value of the misfit became less than $0.5 \mathrm{~s}$ and $1.0 \mathrm{~s}$, respectively, for $P$-phases and $S$ phases.

Magnitudes of these earthquakes were evaluated using

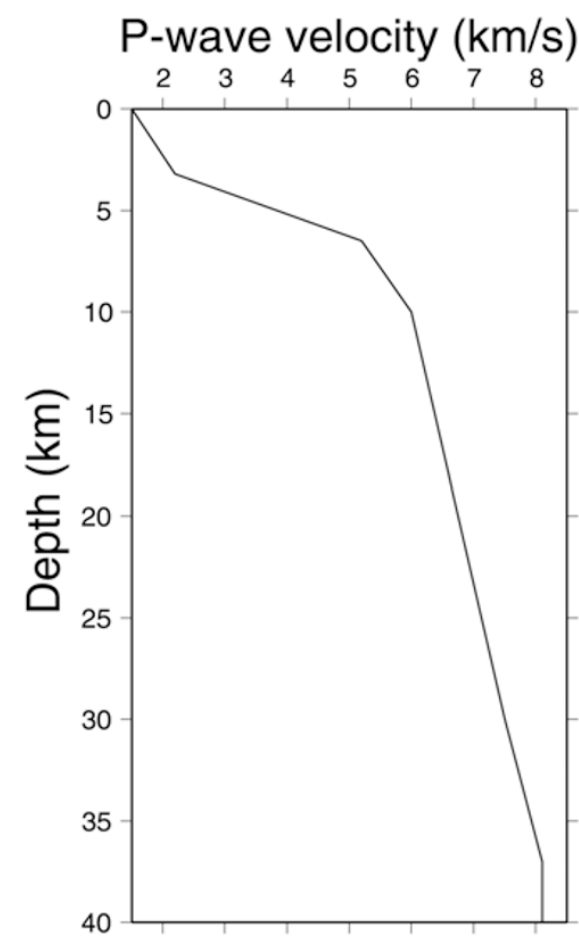

Fig. 2. A $P$-wave seismic velocity model is assumed in the hypocenter determination in this study.

the duration of seismic waves for each event, which is similar to the method of Tsumura (1967). For events reported by USGS, we compared the estimated duration magnitude (Mf-p) with the reported body-wave magnitude (MB). The relation between Mf-p and MB showed a scattered distribution. We adjusted the equation for duration magnitude to match Mf-p to the MB for events of MB 4.6, giving Mf$\mathrm{p}=-1.74+2.85 \log (\mathrm{F}-\mathrm{P})$, where F-P is the event duration in seconds. 
We also inspected polarity of the $P$-wave first motion of vertical component to assess earthquake mechanisms. The amount of observed polarity from 16 OBSs was insufficient to determine focal mechanisms for each event. In most cases, we were able to read only several or more first motion polarity. Therefore, we combined observed polarity data for events of similar location to find representative focal mechanism for the group of earthquakes.

\section{Results}

During 20 February-1 March, 1098 events were located using OBS observation. As shown in Table 2, 17 events were relocated from the USGS PDE catalog between 21 February and 11 March. All located earthquakes, with accuracy of better than $10 \mathrm{~km}$ for both horizontal and depth, are displayed in Fig. 3. All globally determined earthquakes were relocated along the dipping plate that subducted from the Indian Ocean. Some events were relocated with a shift of as much as $50 \mathrm{~km}$ horizontally and $25 \mathrm{~km}$ in depth.

The magnitudes of earthquakes determined by OBSs during the period of 20 February-1 March were distributed from -0.5 to 5 . All events of magnitude $(\mathrm{M})$ greater than 1.5 beneath the OBS network were addressed by our analysis, as suggested from the frequency-magnitude distribution of the located earthquakes.

\section{Discussion}

Most events were located with a dip delineating a subducting plate from the Sunda trench towards Sumatra Island. The area of aftershock seismicity starts at approximately $40 \mathrm{~km}$ from the Sunda trench axis, as defined by the deepest point of the seafloor. Aftershocks extend for $200 \mathrm{~km}$ northeast in the trench orthogonal direction. Fewer earthquakes were located in the upper plate.

Depths of seismicity along the subducting slab were not well determined near the Sunda Trench, but are at least shallower than $30 \mathrm{~km}$. The dip angle of seismicity in the subducting plate would be shallower than $10^{\circ}$ to a point $120 \mathrm{~km}$ from the trench, but the depth of seismicity is ambiguous. Beneath the OBS network, where the depth of seismicity was better determined, the slab seismicity concentrates in an approximately $10-\mathrm{km}$-thick plate. From $120 \mathrm{~km}$ from the trench axis, slab seismicity continues with a dip angle of approximately $10-12^{\circ}$ to the southwestern edge of Aceh Basin (as index C of Fig. 4) at $25 \mathrm{~km}$ depth. The dip angle is slightly deeper than that of the Harvard quick CMT solution of the 26 December event $\left(8^{\circ}\right)$, and similar to those assumed by $\mathrm{Ji}(2005)\left(11^{\circ}\right)$, Yagi (2005), and Hirata et al. (2005) $\left(10^{\circ}\right)$. The focal mechanism of this seismicity as a whole is a down-dip extension type mechanism (Fig. 4).

Seismicity along the subducting slab in the survey area is characterized in two domains in the trench normal direction divided around the southwestern edge of the Aceh Basin. Beneath the Aceh Basin, dipping slab seismicity becomes more active; in addition, their mechanism changes (beyond the index $\mathrm{C}$ in Fig. 4). Transition of the activity is prominent and sudden. The dipping angle of the seismicity seems also to increase to $15-20^{\circ}$, corresponding to this transition. Their focal mechanism changes from a down-dip extension to dip-slip type, as revealed from the dip of planar seismic- ity and nodal angle of the focal mechanism. The dip-slip aftershocks in this area are concentrated in relatively small patches. A small number of upper plate earthquakes are identifiable: they make a branch from the subducting plate interface towards the south of the Aceh Basin. The area of high inter-plate seismicity starts from $25 \mathrm{~km}$ depth and ceases at $50 \mathrm{~km}$ depth at the northern edge of Aceh Basin. Dip-slip aftershocks might suggest an ongoing post-seismic slip at the plate interface beneath the Aceh Basin.

The focal mechanism of the main shock of 26 December 2004 is known to be low-angle dip slip type from seismic moment analysis. Teleseismic analyses (Yamanaka, 2005; $\mathrm{Ji}, 2005)$ suggest co-seismic slip of 2-6 meters in the area between B and C (Fig. 4) during the December main shock. Tsunami analysis (Hirata et al., 2005) also infers large coseismic slip in this area. These analyses indicate that the plate boundary of this area should have slipped during the main shock. However, we now see very inactive dip-slip seismicity in the area. Lack of aftershocks suggests complete strain release during the main shock, and possibly little after-slip occurrence.

The composite focal mechanism of the aftershock suggests that the subducting slab above $25 \mathrm{~km}$ depth is probably under tension, possibly because of slab pull from the subducting plate at deeper depth between regions $\mathrm{C}$ and D. In the future, it will be interesting to observe temporal changes of focal mechanisms and activity in this area. The change of the aftershock focal mechanism might indicate a stress change of the subducting plate in the process of possible postseismic slip and recovery. In this sense, continuous OBS deployments off Sumatra Island, as well as other geodetic measurements such as those using GPS, will greatly benefit our understanding of postseismic processes of large earthquakes.

Almost no aftershocks occur in the subducting slab below Sumatra Island beyond a depth of $50 \mathrm{~km}$ (D in Fig. 4), whereas some earthquakes were seen well beyond that depth in the background seismicity (Engdahl et al., 1998). Analyses of our 10-day OBS data showed that there was also no shallow seismicity in Sumatra Island.

Distribution of upper plate seismicity was concentrated in three band areas along the Sumatra arc: 1) $70 \mathrm{~km}$ from the trench, where the seafloor becomes shallower to $2000 \mathrm{~m}$; 2) in the middle of outer-arc high, approximately $110 \mathrm{~km}$ from the trench axis; and 3) at the southern edge of Aceh Basin, approximately $170 \mathrm{~km}$ from the trench. These three areas have clear correspondence with steep slopes in seafloor topography, as indicated by indexes A-C in Fig. 4. These zones of shallow seismicity might be associated with splay faults.

Correspondence of the upper plate seismicity with the steep topographic slope probably reflects activity of the accretionary prism in the area. At the southern edge of Aceh Basin (C in Fig. 4), the West Andaman Fault is suggested to connect to the Mentawai Fault north of the Simeulue Island (Diament et al., 1992). We observed much higher seismicity in the middle of the outer-arc high (B) and near the Sunda trench (A) than around the suggested West Andaman fault (C). This discrepancy might suggest existence of another fault system in the outer-arc high that is more active 


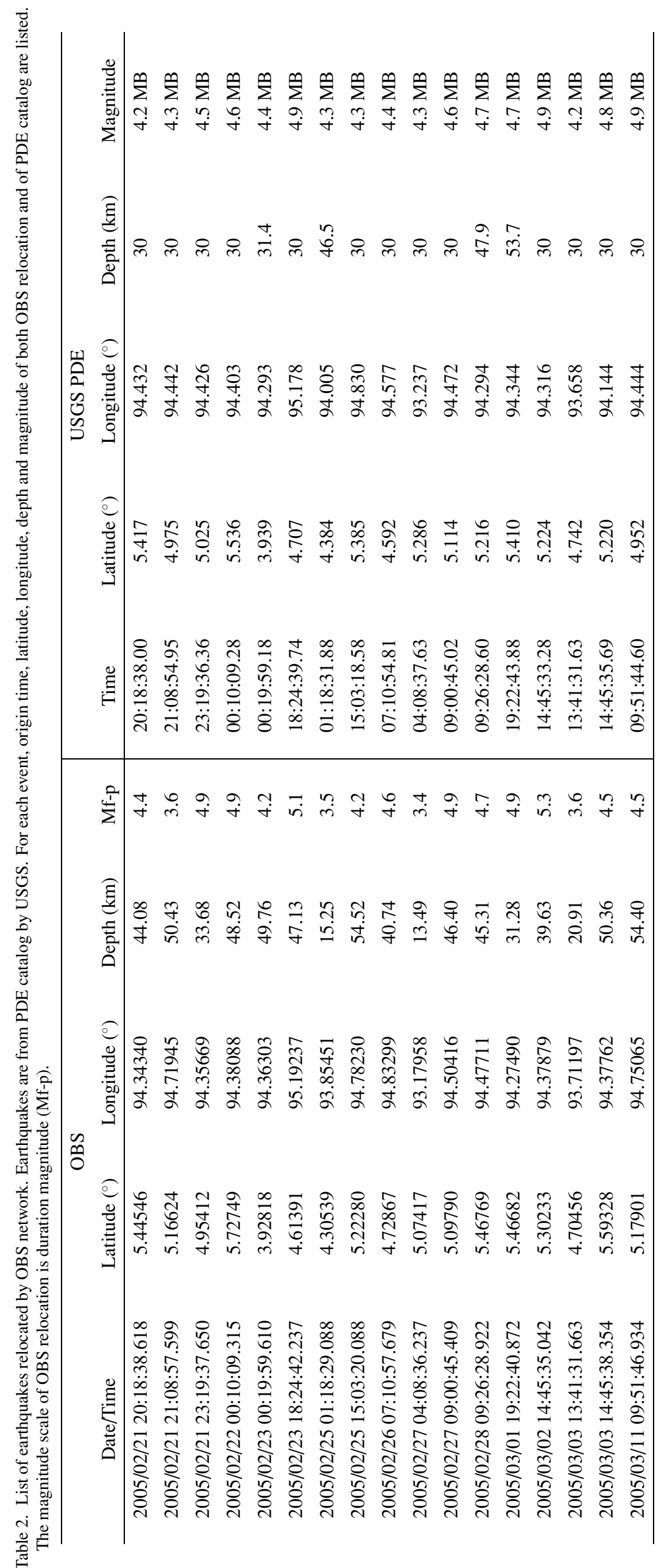



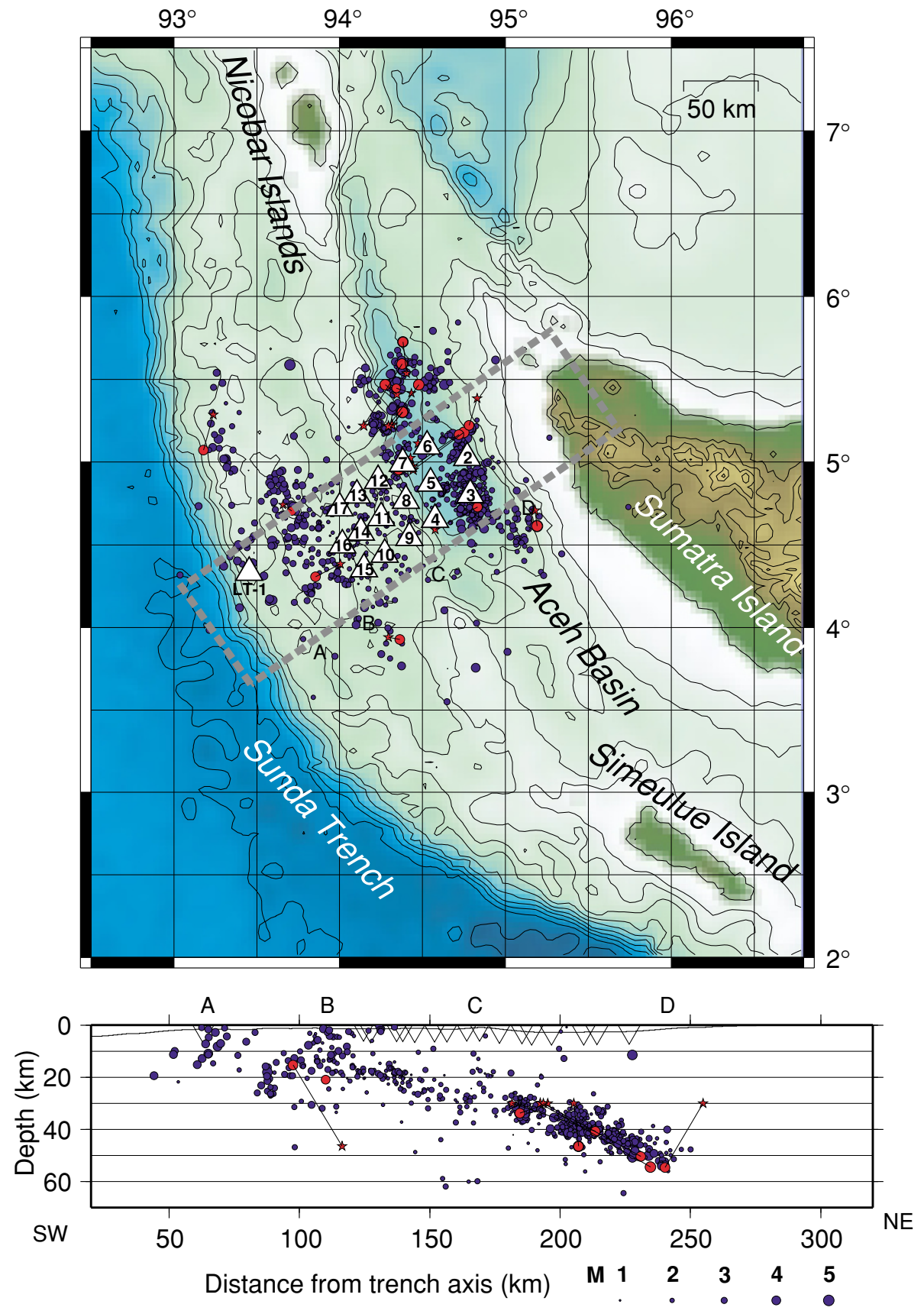

Fig. 3. Seismicity determined from the OBS data of 10-days from 20 February-1 March are shown as blue circles. The circles are scaled according to their duration magnitude (Mf-p) as the bottom scale. The OBS relocated earthquakes from the USGS PDE catalog between 21 February and 11 March are indicated as red circles. Their PDE locations are indicated as red stars. The OBS locations used for hypocenter determination are shown as triangles with their station names. The bottom plate is a cross sectional projection of the hypocenter inside that shown by a dashed box in the map, with horizontal scale showing distance from the Sunda trench. The azimuth of the projection plane is $55^{\circ}$ from the north. Seafloor topography and OBS locations (inverse triangles) are also shown. Indexes A-D in the cross section are also shown in the map.

than the West Andaman fault. We require better seafloor topography data to better understand active faults in this area. The focal mechanism of the shallow seismicity in the accretionary prism is important information to discuss its evolution, but it cannot be determined clearly using the present analysis.

\section{Conclusions}

We deployed the OBS network in February-March 2005, within two months after the devastating Sumatra-Andaman earthquake of 26 December 2004. The OBS network was designed to situate above the area of maximum slip in the earthquake that generated the historical tsunami in the Indian Ocean. We deployed 17 short-term OBS and two longterm OBSs. Short-term OBSs were recovered during the same cruise of deployment by R/V Natsushima after observation for 19-22 days, whereas the long-term OBSs continued observation until the end of July 2005.

The hypocenter distribution from 10-day data of 17 OBS was sufficient to delineate a detailed structure of aftershock seismicity occurring offshore of Sumatra Island. Aftershock seismicity associated with the subducting slab starts 


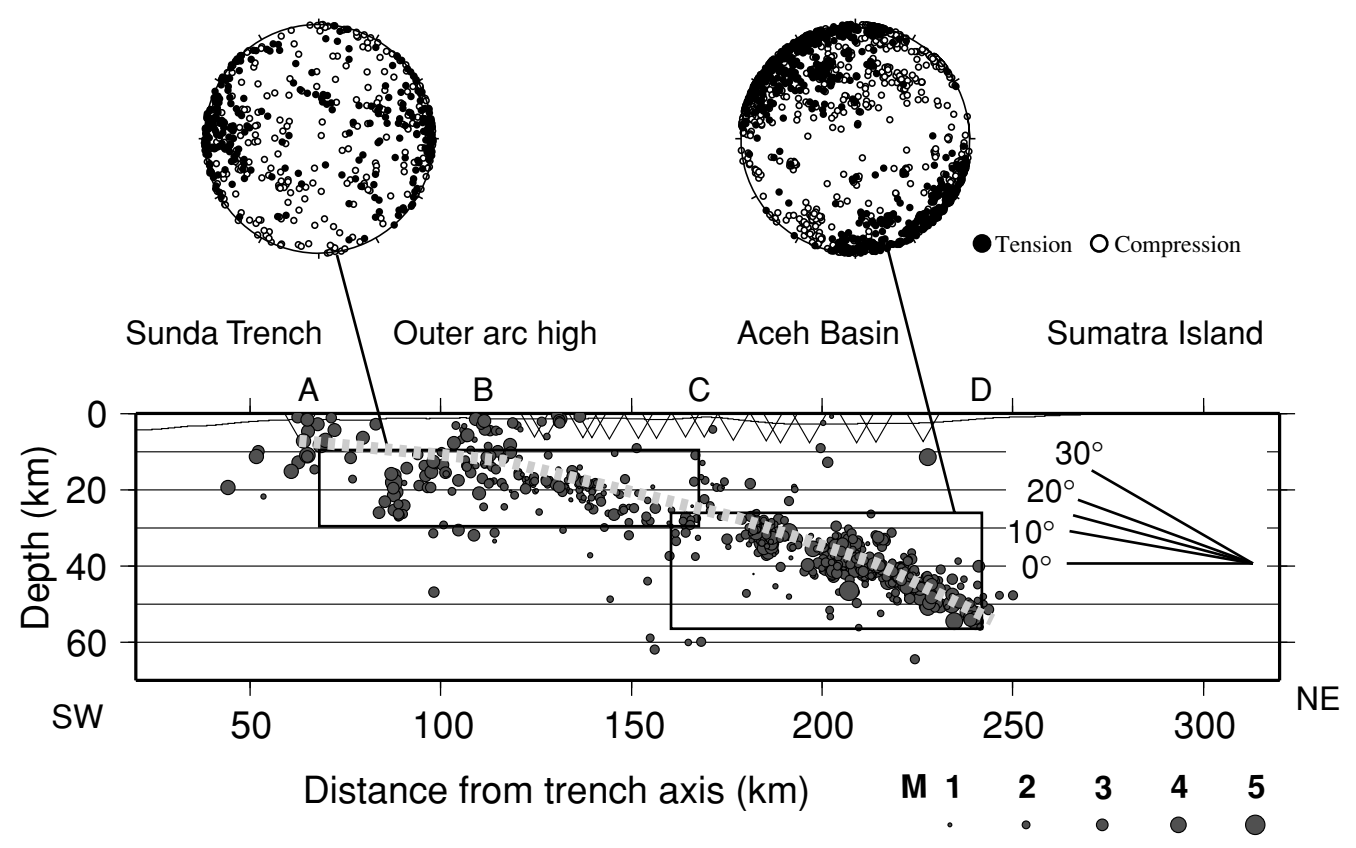

Fig. 4. Illustrated cross section seismicity, as shown by Fig. 3. Dashed gray lines indicate the plate boundary and possible splay faults estimated from OBS seismicity. Composite focal mechanisms are inferred from $P$-wave first motion polarity plots above. The $P$-wave vertical motion polarity data, of which earthquakes are in the solid boxes, are projected into the same cross-sectional plane, as shown by black circles (tension or up), white circles (compression or down). The projected areas are divided by indexes A-D, which correspond to $70 \mathrm{~km}$ from the Sunda Trench (A), the middle mountain of the outer-arc high (B), the Aceh Basin's southwestern edge, (C) and the downdip limit of the aftershock seismicity, (D) in the south of Sumatra Island. The southwestern edge of the profile corresponds to approximately $20 \mathrm{~km}$ from the trench axis.

$40 \mathrm{~km}$ from the Sunda trench axis ceases at $50 \mathrm{~km}$ depth beneath the Aceh Basin approximately $240 \mathrm{~km}$ inward from the trench axis. To the point $120 \mathrm{~km}$ from the trench axis, the dip angle of the subducting plate is shallower than $10^{\circ}$. Beneath the OBS network, most of the aftershocks were confined to within a $10-\mathrm{km}$-thick surface dipping landward. In $120-170 \mathrm{~km}$ from the trench axis, aftershocks consist of a surface with a dip of $10-12^{\circ}$, and are dominated by a dip-extension type mechanism. Beyond the point collocated with the southwestern edge of the Aceh Basin, the aftershock activity becomes higher, and their focal mechanisms are dominated by dip-slip type earthquakes, with a slightly increased dipping angle of $15-20^{\circ}$. These dip-slip aftershocks might suggest occurrence of a post-seismic slip beneath the Aceh Basin.

The OBS observation identified three along-arc bands of shallow seismicity in the upper plate: $70 \mathrm{~km}$ from the Sunda trench, $110 \mathrm{~km}$ inward from the trench, and in the south of the Aceh Basin. Existence of splay faults is inferred in the shallow seismicity areas corresponding also to steep topographic slopes in the accretionary prism, suggesting that the present evolution of the accretionary prism was activated by large earthquakes offshore Sumatra Island.

Acknowledgments. We express our deep appreciation to Captain Fusao Saito, officers and crew of R/V Natsushima for their professional operations that enabled us to make our observations. Operation of OBS deployment and recovery by onboard technicians from Nippon Marine Enterprise, Ltd. was an indispensable part of our scientific research. We appreciate all the onboard scientific party of the NT05-08 Natsushima cruise for their constructive discussion during and after the cruise. Figures were partially prepared using GMT (Wessel and Smith, 1998). This research is supported by special coordination funds for promoting science and technology from the Ministry of Education, Culture, Sports, Science and Technology (MEXT), Japan.

\section{References}

Diament, M., H. Harjono, K. Karta, C. Deplus, D. Dahrin, M. T. Zen, Jr., M. Gerard, O. Lassal, A. Martin, and J. Malod, Mentawai fault zone off Sumatra: A new key to the geodynamics of western Indonesia, Geology, 20, 259-262, 1992.

Engdhal, E., R. van der Hilst, and R. Buland, Global teleseismic earthquake relocation with improved travel times and procedures for depth determination, Bull. Seismol. Soc. Am., 88, 722-743, 1998.

Hirata, K., K. Satake, Y. Tanioka, T. Kuragano, Y. Hasegawa, Y. Hayashi, and N. Hamada, The 2004 Indian Ocean Tsunami: Tsunami Source Model from Satellite Altimetry, Proceedings of 22nd International Tsunami Symposium, Chania, Crete Isl., Greece, 27-29 June, 2005.

Hirata, N. and M. Matsu'ura, Phys. Earth Planet. Inter., 47, 50-61, 1987.

Ji, C., Preliminary Result of the 04/12/26 (Mw 9.0), Off W. Coast of Northern Sumatra Earthquake, 2005. http://www.gps.caltech.edu/_jichen/ Earthquake/2004/aceh/aceh.html

Kennett, B. L. N. and E. R. Engdahl, Traveltimes for global earthquake location and phase identification, Geophys. J. Int., 105, 429-465, 1991.

Kopp, H., E. R. Flueh, D. Klaeschen, J. Bialas, and C. Reichert, Crustal structure of the central Sunda margin at the onset of oblique subduction, Geophys. J. Int., 147, 449-474, 2001.

Stein, S. and E. Okal, Speed and size of the Sumatra Earthquake, Nature, 434, 581-2, 2005.

Tsumura, K., Determination of earthquake magnitude from duration of oscillation, Jishin, 2, 20, 1, 30-40, 1967 (in Japanese).

Wessel, P. and W. H. F. Smith, New, improved version of Generic Mapping Tools released, EOS Trans. Amer. Geophys. U., 79(47), 579, 1998.

Yagi, Y., Preliminary Results of Rupture Process for 2004 Off Coast of Northern Sumatra Giant Earthquake (ver. 1), http://iisee.kenken.go.jp/ staff/yagi/eq/Sumatra2004/Sumatra2004.html, 2005.

Yamanaka, Y., 04/12/26 Off W. Coast of N. Sumatra (revised), EIC Seismological Note: No. 161+, http://www.eri.u-tokyo.ac.jp/sanchu/ Seismo_Note/2004/EIC161ea.html, 2005.

E. Araki (e-mail: araki@jamstec.go.jp), M. Shinohara, K. Obana, T. Yamada, Y. Kaneda, T. Kanazawa, and K. Suyehiro 